\title{
The Impact of Product Nickname on Consumer Product Evaluation
}

\author{
Yanjing Lin, Haiquan Chen \\ School of Management, Jinan University, Guangzhou, China \\ Email: yanjing0712@foxmail.com
}

How to cite this paper: Lin, Y. J., \& Chen, H. Q. (2020). The Impact of Product Nickname on Consumer Product Evaluation. American Journal of Industrial and Business Management, 10, 402-410. https://doi.org/10.4236/ajibm.2020.102026

Received: January 14, 2020

Accepted: February 17, 2020

Published: February 20, 2020

Copyright $\odot 2020$ by author(s) and Scientific Research Publishing Inc. This work is licensed under the Creative Commons Attribution International License (CC BY 4.0).

http://creativecommons.org/licenses/by/4.0/

(c) (i) Open Access

\begin{abstract}
Product nickname is used more frequently in brands' marketing campaigns, replacing the formal product name. Based on this phenomenon, the article studies the mechanism of the effect of product nickname on consumer product evaluation. In this study, consumer psychological ownership is introduced as an intermediary variable to explain the different effects of product nickname and formal product name on consumer product evaluation respectively. Using experimental methods, two experiments are designed to prove the hypotheses. Experiments show that using product nicknames leads to more positive product evaluation by triggering higher levels of psychological ownership.
\end{abstract}

\section{Keywords}

Product Nickname, Consumer Psychological Ownership, Product Evaluation

\section{Introduction}

In recent years, product nickname is frequently used in many brands' marketing campaigns, especially in makeup industry. In reality, female consumers are familiar with product nicknames of many skin-care products, such as "Little White Bottle" (Olay White Radiance Light Perfecting Essence), "Mushroom Water" (DR. ANDREW WEIL FOR ORIGINS Mega-Mushroom Relief \& Resilience Soothing Treatment Lotion) and "Purple Iron" (L'Oreal REVITALIFT FILLER [HA] Eye Cream for Face), while having no idea what the formal names of these products are.

In addition to the makeup industry, product nickname is also commonly employed in some other industries, such as the "Golden Wide Angle" (Nikkor AF-S 17 - $35 \mathrm{~mm}$ f/2.8D IF-ED) from digital brand Nikon, "Green Slim" (Melrose Organic Essential Greens) from health food brand Melrose and "Hairball" (Pandora 
Sparkling \& Polished Lines Charm) from the jeweller Pandora. In word-of-mouth communication and sharing, product nickname often elicits positive emotions and evaluations. Although the above phenomenon continues to emerge in the practice of marketing, we notice that there is no theoretical research on product nickname by far. In the field of marketing research, most of the researches relating to brand name or product name focus on brand naming, such as brand naming rules and characteristics, brand naming decisions and cross-cultural brand name research (Huang \& Chan, 2002; Park, MacInnis, \& Eisingerich, 2015; Hao, 2009). Thus, this article will explore the psychological mechanism of the impact of product nickname on consumer evaluation through empirical research.

By reviewing previous researches about brand naming, consumer psychological ownership and product evaluation, we develop our hypotheses and research model, with two empirical researches being designed to verify the hypotheses.

\section{Theoretical Framework}

\subsection{Product Nickname}

A nickname is defined as "an affectionate appellation" (The Contemporary Chinese Dictionary) or "an informal name for someone or sometimes something, used esp. to show affection, and often based on the person's name or a characteristic of the person" (Cambridge Dictionary). In daily life, people often use nicknames in informal occasions to express closeness and love. Therefore, we define product nickname as an affectionate name given by brands or consumers to serve as a substitution for a product's formal name.

In social context, nickname is an important shorthand for affection that engenders close associations (Bolin, 2005). Some psychological researches also show that nicknames can facilitate satisfaction in interpersonal relationships between partners, family members, and friends (Bruess \& Pearson, 1993; Bell \& Healey, 1992). Similar to the consequences of personal nicknames in the social context, product nicknames may facilitate positive affective responses and forge closer emotional bonds between consumers and the product (Zhang \& Patrick, 2018). As a result, we focus on the realm of positive product nicknames, or those that do not have any negative connotations for the product.

\subsection{Customer Psychological Ownership}

Customer psychological ownership refers to the psychological state that consumer feels the object, such as the enterprise, brand, product, service, etc., is "mine", emphasizing the customer's sense of ownership of the objects related to consumption (Kou, Gao, Zhu, \& Powpaka, 2018). In 2003, organizational behaviorist Pierce and his partners formally defined psychological ownership as a psychological state in which an individual regards an object (material or non-material) or part of it as "own". In addition, they distinguished it from legal ownership (Pierce, Kostova, \& Dirks, 2003). And then, Reb \& Connolly (2007) first introduced the 
concept of psychological ownership to marketing research based on the study of Pierce and criticized the classical interpretation of endowment effect. They argued that the study of endowment effect has neglected the difference between legal ownership and psychological ownership, and related experiments have failed to distinguish the effects of the two. Moreover, they pointed out that psychological ownership is the underlying cause of the endowment effect, rather than the legal ownership. Since then, more and more marketing researches have focused on customer psychological ownership and used it to explain the role of multiple marketing phenomena in product evaluations (Peck \& Shu, 2009; Brasel \& Gips, 2014; Lessard-Bonaventure \& Chebat, 2015).

\section{Hypothesis}

\subsection{The Impact of Product Nickname on Product Evaluation}

Previous studies found that nickname is an important shorthand for affection that engenders close associations (Bolin, 2005). Rhetoric studies have shown that nicknames often convey more emotions and make people feel closer (Du, 1997). Under the Surrounding of social communication, nicknames are often a reflection of intimacy and friendship, and serve as a "tie sign" that carries unique significance in constructing and strengthening interpersonal relationships (Goffman, 1971; Bell \& Healey, 1992). Besides, a number of studies have revealed that consumers believe that some products can have awareness, personality and even interpersonal relationships like humans (Keller, 1993; Aggarwal \& McGill, 2007). We argue that in a similar way to the influence of a person's nickname in a social context, a product nickname can enhance the relationship between consumers and the products by stimulating positive emotional responses and creating a stronger emotional bond between consumers and products (Zhang \& Patrick, 2018), and accordingly, consumers may carry out higher evaluation of the product (Jung, Min, \& Kellaris, 2011). We thus hypothesize:

$\mathrm{H} 1$ : Compared to formal product name, product nickname use leads to a more positive product evaluation.

\subsection{The Mediating Effect of Consumer Psychological Ownership}

Customer psychological ownership refers to the consumer's strong sense of belonging and possession of the product, reflecting a certain emotional connection between the consumer and the product (Zhang, Bai, \& Niu, 2012). When an individual feels that he or she has some kind of emotional connection with the target, he or she assumes that the object or part of it belongs to them (Avey, Avolio, Crossley, \& Luthans, 2009), which lead to the psychological ownership of the target. In the brands' marketing campaigns, the use of product nicknames can promote human-like interpersonal interaction between consumers and products, and allow consumers and products to establish close partnerships, resulting in a higher sense of identity and attachment, which in turn motivate consumers to establish psychological ownership of the product. Once the psychological ownership 
of the product is established, individuals will develop a strong sense of self-identity, which increases the importance and evaluation of the target and has a positive impact on consumer attitudes (Kamleitner \& Feuchtl, 2015). We thus hypothesize:

H2: Compared to formal product name, product nickname use leads to a more positive product evaluation as a result of the enhanced consumer psychological ownership.

\subsection{Research Model}

Based on the above hypotheses, we propose the following research model: Compared with formal product name, the use of product nickname leads to a more positive product evaluation (H1). Compared with formal product name, the use of product nickname leads to a more positive product evaluation as a result of the enhanced consumer psychological ownership (H2). The overall research model is shown in Figure 1.

\section{Experiment}

Based on the previous literature, we propose two hypotheses, and validate these hypotheses through two experiments. Experiment 1 selects skincare product as experimental material to verify the different impact of product nickname and formal product name on consumer product evaluation respectively. Experiment 2 chooses Shampoo, which is more familiar to consumers, as experimental material to test the main effect once again and test the mediating role of psychological ownership.

\subsection{Experiment 1}

\section{Design}

The purpose of Experiment 1 is to examine the impact of product nickname on consumer product evaluation. To this end, we use single-factor (formal product name vs. product nickname) between-group design.

One hundred and thirty undergraduate students (66\% female, $M_{\text {age }}=23$ years) at a large university in Guangdong, China participate in this online survey. Participants are randomly assigned to two conditions (formal product name and product nickname).

\section{Process}

Participants are asked to imagine that they are using social networking site, on which they are presented with an advertisement about a skin care product.

In the formal product name condition, participants read a piece of advertisement.

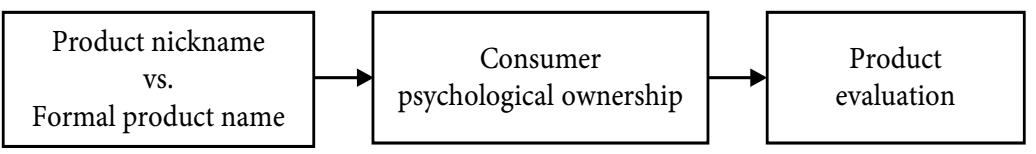

Figure 1. The impact of product nickname on consumer product evaluation. 
"The dryness in autumn and winter leads to problems such as dehydrated skin, enlarged pores and skin wrinkling. RNA NEW AGE Essence containing breakthrough skin tightening technology will repair your skin and help to restore its smoothness and tenderness. Applying the RNA NEW AGE Essence after cleaning your face in the morning and evening, its small molecule components can quickly penetrate into the bottom of the skin, fill the skin gap in multiple directions, and revitalize your skin!"

In the product nickname condition, participants read another piece of advertisement.

"The dryness in autumn and winter leads to problems such as dehydrated skin, enlarged pores and skin wrinkling. Little Red Bottle containing breakthrough skin tightening technology will repair your skin and help to restore its smoothness and tenderness. Applying the Little Red Bottle after cleaning your face in the morning and evening, its small molecule components can quickly penetrate into the bottom of the skin, fill the skin gap in multiple directions, and revitalize your skin!"

Then, all participants are asked to fill out the questionnaire to measure their product evaluation. Product evaluation is evaluated on four semantic differential items with seven-point response alternatives (negative-positive, bad-good, uninteresting-interesting, unattractive-attractive) (Femke \& Rik, 2017), which are averaged to create the evaluation scale.

\section{Result}

An ANOVA with the two experimental conditions as the independent variable and product evaluation as the dependent variable revealed a significant main effect, as shown in Figure 2. Compared to formal product name, product nickname use leads to a more positive product evaluation $\left(M_{\text {product nickname }}=5.22\right.$, $\left.M_{\text {formal product name }}=4.87, F(1,129)=4.861, p<0.05\right)$, supporting our hypothesis $\mathrm{H} 1$.

\section{Discussion}

Experiment 1 demonstrates that using product nickname result in a more positive product evaluation. As described above, we believe that findings occur precisely because consumers generated different level of psychological ownership.

\subsection{Experiment 2}

\section{Design}

The purpose of Experiment 2 is to re-examine the impact of product nickname on consumer product evaluation, and further, verify the mediating role of psychological ownership. We also use single-factor (formal product name vs. product nickname) between-group design.

Ninety undergraduate students (62\% female, $M_{\text {age }}=25$ years) at a large university in Guangdong participate in this online study. Participants are randomly assigned to two conditions (formal product name and product nickname). 


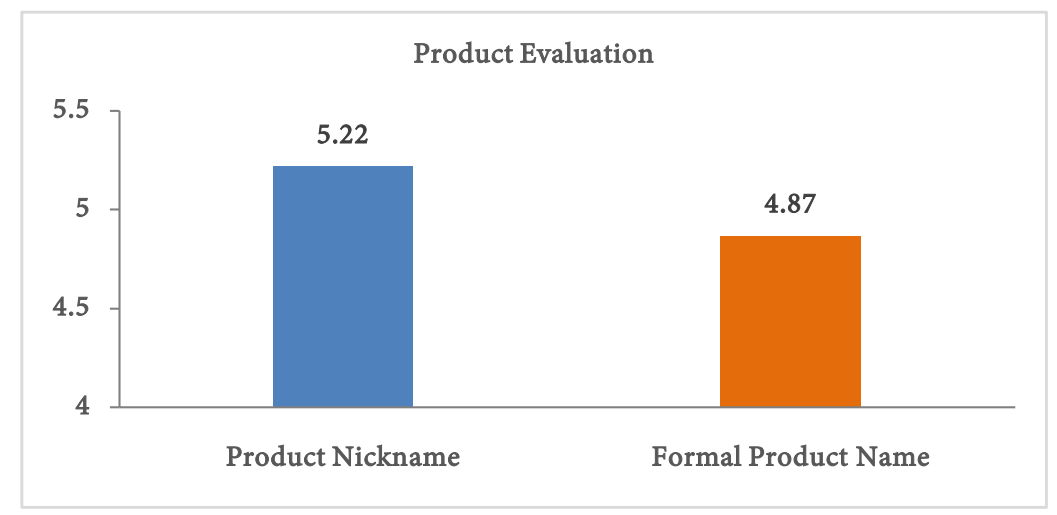

Figure 2. Results of Experiment 1.

\section{Process}

Participants are asked to imagine that they are using social networking site. Then Participants have watched an advertisement of Lush shampoo bar.

In the formal product name condition, participants read a piece of advertisement.

"The Internet celebrity Lush shampoo bar-New Shampoo Bar, has freshest handmade, small size and light weight, rich in natural plant ingredients of the many advantages. Cinnamon Leaf Oil boosts blood flow, stimulating the hair follicles. An infusion of Peppermint and clove helps to stimulate the scalp, promote healthy hair and adds a glorious shine to your hair."

In the product nickname condition, participants read another piece of advertisement.

"The Internet celebrity Lush shampoo bar-Little Red Hat, has freshest handmade, small size and light weight, rich in natural plant ingredients of the many advantages. Cinnamon Leaf Oil boosts blood flow, stimulating the hair follicles. An infusion of Peppermint and clove helps to stimulate the scalp, promote healthy hair and adds a glorious shine to your hair."

Then, all partners are asked to fill out the questionnaire to measure the product evaluation and consumer psychological ownership. Product evaluation is measured using the same scale as in Experiment 1. Consumer psychological ownership is measured with five items- "I feel like this is my New Shampoo Bar/Little Red Hat"; "I feel like that this New Shampoo Bar/Little Red Hat belongs to me"; "I feel a strong sense of closeness with the New Shampoo Bar/Little Red Hat"; "I feel connected to the New Shampoo Bar/Little Red Hat" and "The New Shampoo Bar/Little Red Hat incorporates a part of myself", each on a 7-point scale anchored by endpoints "strongly disagree" and "strongly agree" (Peck \& Shu, 2009; Fuchs, Prandelli, \& Schreier, 2010), which are averaged to create the consumer psychological ownership scale.

\section{Result}

An ANOVA with the two experimental conditions as the independent variable and product evaluation as the dependent variable reveals a significant main effect once again $\left(M_{\text {product nickname }}=5.77, M_{\text {formal product name }}=5.16, F(1,89)=13.178\right.$, 
$p<0.001$ ), supporting our hypothesis $\mathrm{H} 1$.

We then conduct a bootstrapping analysis that generates a sample size of 5000 (Model 4) to test the Mediation effect. With the two experimental conditions as the independent variable, product evaluation as the dependent variable and consumer psychological ownership as the mediator, a 95\% confidence interval (CI) for the indirect effect is significant and excluded zero (95\% CI: $-0.5190,-0.0945$ ), which provides the evidence of the mediation effect of consumer psychological ownership, supporting our hypothesis $\mathrm{H} 2$.

\section{Discussion}

Experiment 2 re-examines the positive impact of product nickname on consumer product evaluation and test the mediator effect of consumer psychological ownership. Thus, the research model is totally tested.

\section{General Discussion}

In this study, we use empirical research to prove the research hypotheses through two experiments. 1) Compared to formal product name, product nickname use leads to a more positive product evaluation; 2) Compared to formal product name, product nickname use leads to a more positive product evaluation as a result of the enhanced customer psychological ownership. In other words, our study shows that in social marketing, using product nicknames can stimulate higher consumer psychological ownership and lead to more positive product evaluation.

\section{Implication}

In brand marketing research field, most of the researches related to brand name or product name are about brand naming and there are few researches on product naming. By studying the mechanism of the effect of product nickname on consumer product evaluation and introducing consumer psychological ownership as an intermediary variable, this study fills this research gap and enriches the research of brand marketing.

For companies, brands could give the product a social nickname based on product characteristics to stimulate the consumer psychological ownership, so as to effectively enhance consumer's product evaluation and further affect consumer's product attitude and willingness to buy.

\section{Limits and future research}

In this paper, we select rigorous materials and use different experimental materials to enhance robustness. However, there are still some problems with this study. For revealing the effects of product nickname, we only focus on the difference in consumer product evaluation, without further measuring the consumers' willingness to buy and willingness to pay, etc. Future research might explore these issues.

\section{Conflicts of Interest}

The authors declare no conflicts of interest regarding the publication of this paper. 


\section{References}

Aggarwal, P., \& McGill, A. L. (2007). Is That Car Smiling at Me? Schema Congruity as a Basis for Evaluating Anthropomorphized Products. Journal of Consumer Research, 34, 468-479. https://doi.org/10.1086/518544

Avey, J. B., Avolio, B. J., Crossley, C. D., \& Luthans, F. (2009). Psychological Ownership: Theoretical Extensions, Measurement, and Relation to Work Outcomes. Journal of Organizational Behavior, 30, 173-191. https://doi.org/10.1002/job.583

Bell, R. A., \& Healey, J. G. (1992). Idiomatic Communication and Interpersonal Solidarity in Friends' Relational Cultures. Human Communication Research, 18, 307-335. https://doi.org/10.1111/j.1468-2958.1992.tb00555.x

Bolin, A. (2005). The Effects of First Name Stereotypes on Ratings of Job Applicants: Is There a Difference between Bill and William. American Journal of Psychological Research, 1, 11-20.

Brasel, S. A., \& Gips, J. (2014). Tablets, Touchscreens, and Touchpads: How Varying Touch Interfaces Trigger Psychological Ownership and Endowment. Journal of Consumer Psychology, 24, 226-233. https://doi.org/10.1016/j.jcps.2013.10.003

Bruess, C. J. S., \& Pearson, J. C. (1993). "Sweet Pea" and "Pussy Cat": An Examination of Idiom Use and Marital Satisfaction over the Life Cycle. Journal of Social and Personal Relationships, 10, 609-615. https://doi.org/10.1177/0265407593104009

Du, W. X. (1997). Brief Discussion of the Cultural Constraints of Chinese Nicknames. Contemporary Rhetoric, 2, 15-17.

Femke, V. H., \& Rik, P. (2017). Out-of-Category Brand Imitation: Product Categorization Determines Copycat Evaluation. Journal of Consumer Research, 44, 816-832. https://doi.org/10.1093/jcr/ucx065

Fuchs, C., Prandelli, E., \& Schreier, M. (2010). The Psychological Effects of Empowerment Strategies on Consumers' Product Demand. Journal of Marketing, 74, 65-79. https://doi.org/10.1509/jmkg.74.1.65

Goffman, E. (1971). Relations in Public: Microstudies of the Public Order. New York: Basic.

Hao, J. (2009). Interdisciplinary and Cross-cultural Research on Brand Name Under the Globalization Context. Foreign Economics \& Management, 31, 51-58.

Huang, Y. Y., \& Chan, A. K. K. (2002). The Principle and Special Features in Chinese Branding. Nankai Business Review, 1, 68-71.

Jung, J. M., Min, K. S., \& Kellaris, J. J. (2011). The Games People Play: How the Entertainment Value of Online Ads Helps or Harms Persuasion. Psychology \& Marketing, 28, 661-681. https://doi.org/10.1002/mar.20406

Kamleitner, B., \& Feuchtl, S. (2015). “As If It Were Mine”: Imagery Works by Inducing Psychological Ownership. Journal of Marketing Theory and Practice, 23, 208-223.

Keller, K. L. (1993). Conceptualizing, Measuring, and Managing Customer-based Brand Equity. Journal of Marketing, 57, 1-22. https://doi.org/10.1177/002224299305700101

Kou, Y., Gao, M., Zhu, Y. H., \& Powpaka, S. (2018). A Literature Review of Customer Psychological Ownership and Prospects. Foreign Economics \& Management, 40, 105-122.

Lessard-Bonaventure, S., \& Chebat, J. C. (2015). Psychological Ownership, Touch, and Willingness to Pay for an Extended Warranty. Journal of Marketing Theory and Practice, 23, 224-234.

Park, C. W., MacInnis, D. J., \& Eisingerich, A. B. (2015). Brand Architecture Design and Brand Naming Decision. In F. Dall'Olmo Riley, J. Singh, \& C. Blankson (Eds.), The Routledge Companion to Contemporary Brand Management. London: Routledge. 
Peck, J., \& Shu, S. B. (2009). The Effect of Mere Touch on Perceived Ownership. Journal of Consumer Research, 36, 434-447. https://doi.org/10.1086/598614

Pierce, J. L., Kostova, T., \& Dirks, K. T. (2003). The State of Psychological Ownership: Integrating and Extending a Century of Research. Review of General Psychology, 7, 84-107. https://doi.org/10.1037/1089-2680.7.1.84

Reb, J., \& Connolly, T. (2007). Possession, Feelings of Ownership and the Endowment Effect. Judgment and Decision Making, 2, 107-114.

Zhang, H., \& Liu, W. D. (2016). The Relations Between Brand Psychological Ownership, Customer Engagement and Self-Brand Connection: Using Tourism Brand as Example. Journal of Brand Research, 6, 25-38.

Zhang, H., Bai, C. H., \& Niu, Z. B. (2012). Study on the Relationship between Brand Psychological Ownership, Brand Commitment and Brand Citizenship Behavior. Journal of Management Science, 4, 79-90.

Zhang, Z., \& Patrick, V. M. (2018). Call Me Rollie! The Role of Brand Nicknames in Shaping Consumer-Brand Relationships. Journal of the Association for Consumer Research, 3, 147-162. https://doi.org/10.1086/697074 